\title{
The role of obesity in carotid plaque instability: interaction with age, gender, and cardiovascular risk factors
}

\author{
Valentina Rovella ${ }^{1 \dagger}$, Lucia Anemona ${ }^{2 \dagger}$, Marina Cardellini ${ }^{3}$, Manuel Scimeca ${ }^{3,4,5}$, Andrea Saggini ${ }^{2}$, \\ Giuseppe Santeusanio², Elena Bonanno ${ }^{2}$, Manuela Montanaro ${ }^{2}$, lacopo Maria Legramante ${ }^{6}$, Arnaldo Ippoliti ${ }^{7}$, \\ Nicola Di Daniele ${ }^{1}$, Massimo Federici ${ }^{6}$ and Alessandro Mauriello ${ }^{2^{*}}$
}

\begin{abstract}
Background: In the last decade, several studies have reported an unexpected and seemingly paradoxical inverse correlation between BMI and incidence of cardiovascular diseases. This so called "obesity paradox effect" has been mainly investigated through imaging methods instead of histologic evaluation, which is still the best method to study the instability of carotid plaque. Therefore, the purpose of our study was to evaluate by histology the role of obesity in destabilization of carotid plaques and the interaction with age, gender and other major cerebrovascular risk factors.

Methods: A total of 390 carotid plaques from symptomatic and asymptomatic patients submitted to endarterectomy, for whom complete clinical and laboratory assessment of major cardiovascular risk factors was available, were studied by histology. Patients with a BMI $\geq 30.0 \mathrm{~kg} / \mathrm{m}^{2}$ were considered as obese. Data were analyzed by multivariate logistic regression and for each variable in the equation the estimated odds ratio (OR) was calculated.

Results: Unstable carotid plaque OR for obese patients with age $<70$ years was 5.91 (95\% Cl 1.17-29.80), thus being the highest OR compared to that of other risk factors. Unstable carotid plaque OR decreased to 4.61 ( $95 \% \mathrm{Cl} 0.54-$ 39.19) in males $\geq 70$ years, being only 0.93 (95\% Cl 0.25-3.52) among women. When obesity featured among metabolic syndrome risk factors, the OR for plaque destabilization was $3.97(95 \% \mathrm{Cl} 1.81-6.22)$, a significantly higher value compared to $\mathrm{OR}$ in non-obese individuals with metabolic syndrome $(\mathrm{OR}=1.48 ; 95 \% \mathrm{Cl} 0.86-2.31)$. Similar results were obtained when assessing the occurrence of acute cerebrovascular symptoms.

Conclusions: Results from our study appear to do not confirm any paradoxical effect of obesity on the carotid artery district. Conversely, obesity is confirmed to be an independent risk factor for carotid plaque destabilization, particularly in males aged $<70$ years, significantly increasing such risk among patients with metabolic syndrome.
\end{abstract}

Keywords: Obesity, Stroke, Carotid, Histology, Metabolic syndrome, Age, Gender

\section{Introduction}

Obesity is often accompanied by other comorbidities increasing the risk of atherosclerosis, particularly hypertension, dyslipidemia, and type 2 diabetes mellitus, the combination of which is observed in the metabolic

\footnotetext{
*Correspondence: alessandro.mauriello@uniroma2.it

'Valentina Rovella and Lucia Anemona contributed equally to this work

${ }^{2}$ Anatomic Pathology, Department of Experimental Medicine

and Surgery, University of Rome "Tor Vergata", Via Montpellier 1, 00133 Rome, Italy

Full list of author information is available at the end of the article
}

syndrome $[1,2]$. Despite this mechanistic evidence, the role of obesity as a significant risk factor for development of clinically manifest cardiovascular disease [2-4] is still controversial with both positive and neutral studies $[5,6]$. More recently, several studies underlined the so-called "obesity survival paradox" in patients suffering from acute myocardial infarction [2, 7-9]. An analogous paradoxical influence of obesity was also demonstrated in an autopsy study on the aortic district [10].

The influence of obesity on atherosclerotic disease in the carotid district is still unclear. While obesity is 
regarded as a well-established risk factor for stroke [1114], some studies reported significantly lower mortality rates in stroke patients with higher body mass index (BMI) values [15-17]. Such conflicting evidence may be due to the fact that, in the carotid district, the atherosclerotic disease has been mainly investigated through imaging methods, instead of histologic evaluation. Nevertheless, histology is regarded as the gold standard for assessing the degree of atherosclerotic plaque vulnerability as well as the presence of cap rupture and acute luminal thrombosis, which is the major source of emboli in the cerebral circulation [18-20]. Furthermore, it remains still unknown whether the pro- or anti-atherosclerotic effect of obesity may be affected by age, gender and other major cerebrovascular risk factors.

The main target for preventing ischemic cerebrovascular events is the identification of vulnerable plaques, prior to the onset of acute clinical symptoms. Thus, the evaluation of any correlation between obesity and plaque histologic features may be of significant clinical relevance. Here we show results from a clinicopathological evaluation of the role of obesity in the destabilization of carotid plaques and development of cerebrovascular events.

\section{Materials and methods}

\section{Case selection}

A total of 390 carotid specimens from the Interinstitutional Carotid Tissue Bank (ICTB) [18] were studied; carotid samples were collected from 265 symptomatic patients (major stroke or transient ischemic attack; 67.9\%) and 125 asymptomatic patients (32.1\%) underwent to surgical carotid endarterectomy (CEA) at the University of Rome Tor Vergata (Italy).

Among symptomatic patients, only those diagnosed with thrombo-embolism due to carotid atherosclerosis were included, whereas patients referred to any other cause of thrombo-embolism assessed by clinical examination and imaging were excluded. Specifically, cerebral CT scan study and angiographic examination of extra and intracranial carotid arteries and their branches were performed as routine pre-operative evaluation in all patients. Exclusion factors from the study were: (1) a possible cardiac source of embolization (rhythm disorders, recent myocardial infarction, stenosis, prolapse or calcification of mitral valve, left ventricular thrombus, mechanical cardiac valves, atrial myxoma, endocarditis, dilated cardiomyopathy, a patent foramen ovale), (2) stenosis greater than $50 \%$ of Willis circle.

All asymptomatic patients showed a carotid stenosis of at least $60 \%$. For each patient, one carotid sample was collected. Informed consent was obtained from all subjects enrolled in this study. Study protocol adhered to ethical guidelines of the 2000 Declaration of Helsinki and was granted an a priori approval by the IRBs of our Institution.

\section{Risk factors}

Patients with a BMI $\geq 30.0 \mathrm{~kg} / \mathrm{m}^{2}$ were considered as obese, as defined by the American Heart Association (AHA) criteria [13]. Additional cardiovascular risk factors were defined as follows: (a) hypertension: systolic $\mathrm{BP} \geq 140 \mathrm{mmHg}$ and/or a diastolic $\mathrm{BP} \geq 90 \mathrm{mmHg}$ corresponding to stage 1 of JNC7 [21] and stage 2 of 2017 ACC/AHA guidelines [22]. Any patient under previous treatment with antihypertensive drugs was considered as being included under the diagnosis of hypertension; (b) diabetes mellitus: fasting blood glucose $>126 \mathrm{mg} / \mathrm{dL}$ and/or oral glucose-lowering treatment and/or insulin therapy; (c) smoke: patients with tobacco dependence as well as those who had stopped smoking for $<5$ years; (d) metabolic syndrome, as defined in the AHA scientific statement [1]. In order to evaluate the dyslipidemia [23] low-density lipoprotein cholesterol (LDL-C) was calculated by the Friedewald equation [24]: LDL-C $=$ cholesterol - [HDL-C + (triglycerides/5)]. A value of LDL-C of $>100 \mathrm{mg} / \mathrm{dL}$ was utilized as cut-off between high and low levels. Treatment with statins was also used as a criterion for inclusion in this category.

\section{Histology}

Sampling and histological methods have been previously reported $[18,25,26]$. Intraoperatively, carotid plaques were removed in block, immediately fixed in $10 \%$ buffered formalin, transversely cut every $5 \mathrm{~mm}$, paraffin-embedded, and stained with hematoxylin-eosin and Movat stain. The entire plaque was evaluated by histology.

Plaques were classified into two categories according to the modified AHA atherosclerosis classification [27]: stable plaques and unstable plaques. Unstable plaques included those with cap rupture associated with acute thrombosis or with organized thrombi as well as vulnerable plaques or thin-cap fibroatheromas (TCFAs), the latter being characterized by the presence of a fibrous cap $<165 \mu \mathrm{m}$-thick and a marked infiltration by CD68 positive macrophages (at least $25 / \mathrm{hpf}$ ), with no plaque rupture. Stable plaques included fibroatheromatous plaques with thick fibrous caps $(>165 \mu \mathrm{m})$ associated with the presence of calcification and a variable necrotic core [28], as well as healed plaques, defined as those showing multilayers of fibrous tissue.

\section{Statistical analysis}

Data were analyzed using SPSS version 16.0 (SPSS Inc, Chicago, Ill) software. Continuous variables were expressed as the mean $\pm \mathrm{SD}$. The normal distribution 
of the data was assessed by the Shapiro-Wilk test. Continuous variables were compared using the independent Student t-test or the Wilcoxon rank sum test. Categorical data were analysed using the Chi square test or the Fisher exact test.

Multivariate analysis using stepwise logistic regression (using the "enter" method for variable selection) was utilized to identify independent risk factors which significantly correlate with the presence of cerebrovascular symptoms (symptomatics vs. asymptomatics) or with an unstable carotid plaque. Multivariate analysis was performed in two models. One model was adjusted for the following parameters: age, gender and all the risk factors associated to metabolic syndrome (hypertension, diabetes, smoking habit, dyslipidemia (LDL-C), obesity. A second model was adjusted for age, gender, smoking habit, high cholesterol levels and metabolic syndrome, with or without obesity.

For each of the independent variables in the model, logistic regression was also used to estimate the coefficient $(B)$, the estimated odds ratio $(\mathrm{OR})[\exp (\mathrm{B})]$ and the $95 \%$ confidence interval for $\exp (\mathrm{B})$ The statistical analyses were performed considering (a) all patients, (b) the male and female subgroups, (c) two cohorts of male patients divided according to the value of the median of age, i.e. 70 years.
A 2-tailed $\mathrm{p}$ value $<0.05$ was considered statistically significant.

\section{Results}

Baseline data

As shown in Table 1, the mean age of the study population at the time of CEA was $69.8 \pm 7.2$ years; $273(70.0 \%)$ were male and 117 female (30.0\%); 265 patients (67.9\%) suffered ipsilateral major stroke or TIA (31.9\%), while 125 (32.1\%) were asymptomatic individuals who underwent CEA for high grade carotid stenosis.

All patients had at least one risk factor. Hypertension (in $69.5 \%$ of cases) and dyslipidemia (in $65.9 \%$ of patients) were the risk factors most frequently observed. In particular, 43 patients $(11.0 \%)$ showed a BMI $>30 \mathrm{~kg} / \mathrm{m}^{2}$ (obesity). Metabolic syndrome was observed in 123 cases (31.5\%) and in 39 of these obesity constituted one of its components. Treatment with statins and diuretics was administered to 37.7 and $57.2 \%$ of patients, respectively. All patients in the post-operative and follow-up periods were treated with aspirin $(100 \mathrm{md} / \mathrm{die})$.

The histological examination showed in 253 patients (64.9\%) the presence of unstable plaque (with acute thrombosis and/or TCFA), whereas in 137 (35.1\%) the presence of the stable one (Fig. 1). Unstable plaques were significantly associated with the presence of symptoms

\section{Table 1 Baseline characteristics of patients}

\begin{tabular}{|c|c|c|c|c|}
\hline & $\begin{array}{l}\text { All cases } \\
\mathrm{N}=390\end{array}$ & $\begin{array}{l}\text { Symptomatic patients } \\
\mathrm{N}=265\end{array}$ & $\begin{array}{l}\text { Asymptomatic, patients } \\
\mathrm{N}=125\end{array}$ & $\begin{array}{l}\text { Symptomatics vs. asymptomatics } \\
\text { p }\end{array}$ \\
\hline Age, mean (SD) & $69.80(7.21)$ & $70.11(7.39)$ & $69.17(6.80)$ & 0.23 \\
\hline \multicolumn{5}{|l|}{ Gender } \\
\hline M & $273(70.0 \%)$ & $117(30.0 \%)$ & $194(73.2 \%)$ & 0.04 \\
\hline $\mathrm{F}$ & $71(26.8 \%)$ & $79(63.2 \%)$ & $46(36.8 \%)$ & \\
\hline Obesity & $43(11.0 \%)$ & $37(14.0 \%)$ & $6(4.8 \%)$ & 0.007 \\
\hline Hypertension & $271(69.5 \%)$ & $198(74.7 \%)$ & $73(58.4 \%)$ & 0.001 \\
\hline Diabetes & $94(24.1 \%)$ & $65(24.5 \%)$ & $29(23.2 \%)$ & 0.77 \\
\hline Smoking habit & $227(58.2 \%)$ & $152(57.4 \%)$ & $75(60.0 \%)$ & 0.62 \\
\hline Dyslipidemia (high LDL-C) & 257 (65.9\%) & $185(69.8 \%)$ & $72(57.6 \%)$ & 0.02 \\
\hline Metabolic syndrome & $123(31.6 \%)$ & $93(35.2 \%)$ & $30(24.0 \%)$ & 0.03 \\
\hline \multicolumn{5}{|l|}{ Drugs } \\
\hline Statins & $147(37.7 \%)$ & $101(38.1 \%)$ & $46(36.8 \%)$ & 0.80 \\
\hline Diuretics & $223(57.2 \%)$ & $158(59.6 \%)$ & $65(52.0 \%)$ & 0.16 \\
\hline $\begin{array}{l}\text { Previous myocardial infarction/unstable } \\
\text { angina }\end{array}$ & $52(13.3 \%)$ & $37(14.0 \%)$ & $15(12.0 \%)$ & 0.59 \\
\hline \multicolumn{5}{|l|}{ Histological type of carotid plaque } \\
\hline Stable plaques & 137 (35.1\%) & $51(19.2 \%)$ & $86(68.8 \%)$ & 0.001 \\
\hline Unstable plaques & $253(64.9 \%)$ & $214(80.8 \%)$ & $39(31.2 \%)$ & \\
\hline Ruptured/thrombotic & $123(45.5 \%)$ & $123(45.5 \%)$ & 0 & \\
\hline TCFA & $72(18.5 \%)$ & $33(12.5 \%)$ & $39(31.2 \%)$ & \\
\hline Thrombus in organization & $58(14.9 \%)$ & $58(14.9 \%)$ & 0 & \\
\hline
\end{tabular}


$(\mathrm{p}=0.001)$ (Table 1$)$. The only unstable plaques observed in the asymptomatic group were represented by TCFAs.

\section{Correlation among risk factors, symptoms and type of plaque}

Univariate analysis reported in Table 2 demonstrated that obesity $(p=0.006)$, gender $(p=0.03)$, hypertension $(\mathrm{p}=0.001)$ and dyslipidemia $(\mathrm{p}=0.01)$ were the risk factors significantly correlated with the presence of unstable carotid plaques characterized by a high degree of inflammation, thinning and rupture of the cap associated with an acute thrombosis. In addition a significant correlation was also observed between the presence of the risk factors mentioned above and the presence of symptoms (Table 1).

Multivariate analysis confirmed these results and showed an OR (increased risk of having an unstable plaque) of 2.58 (95\% CI 1.08-6.19) for obesity. When the presence of metabolic syndrome was considered in the multivariate analysis, the latter had a highly significant independent effect $(\mathrm{p}=0.001)$ with an OR of $2.55(95 \%$ CI 1.61-4.90). If we considered patients with metabolic syndrome and obesity, the value of OR increased to 3.97 (95\% CI 1.81-6.22) compared to the value of 1.48 (95\% CI $0.86-2.31$ ) when obesity was not included in the metabolic syndrome (Table 2).

Similar results were obtained when the presence of cerebrovascular clinical symptoms, and not the histological finding of unstable plaques, was considered as the dependent variable in the uni- and multivariate analysis (Table 3). Patients with BMI > 30 and metabolic syndrome were those at highest risk, with an OR of 3.15 (95\% CI 1.85-5.10) (Table 3).

\section{Correlation among risk factors, gender and type of plaque}

A separate analysis was performed in male and female patients, as reported in Table 4.

For male patients the risk factors significantly associated with the presence of unstable carotid plaques were: age $(\mathrm{p}=0.03)$, hypertension $(\mathrm{p}=0.001)$ and obesity $(\mathrm{p}=0.01)$. However, obesity showed the higher OR $(=$ $5.06,95 \%$ CI $1.42-18.11$ ) as compared to those of other risk factors.

In the female patients obesity was not significantly associated to the presence of unstable plaques $(p=0.92)$. In this subgroup of patients only hypertension was predictive of carotid plaque instability $(\mathrm{p}=0.005)$.

Since in male patients age was an independent risk factor for carotid plaque instability, a different analysis was performed considering (a) male patients with $<70$ years and (b) those with $\geq 70$ years, value corresponding to the median value of age (Table 5). In patients aged $<70$ years obesity showed the highest value of OR observed in all the analyses performed, with a value of 5.91 (95\% CI $1.17-29.80$ ). In aged patients ( $\geq 70$ years) the value of $\mathrm{OR}$ decreased to 4.61 (95\% CI 0.54-39.19).

\section{Discussion}

Results reported in this study support the role of obesity as an independent risk factor for carotid plaque destabilization among male patients $<70$ years-old, while in older patients and women the effect of obesity appears to be less consistent. Indeed, among patients with BMI >

Table 2 Correlation between risk factors and type of carotid plaques in all cases

\begin{tabular}{|c|c|c|c|c|c|}
\hline & \multirow{2}{*}{$\begin{array}{l}\text { Unstable plaques } \\
\mathrm{N}=253\end{array}$} & \multirow{2}{*}{$\begin{array}{l}\text { Stable plaques } \\
\mathrm{N}=137\end{array}$} & \multirow{2}{*}{$\begin{array}{l}\text { Univariate analysis } \\
\mathrm{p}\end{array}$} & \multicolumn{2}{|c|}{ Multivariate analysis } \\
\hline & & & & $\mathrm{p}$ & OR $(95 \% \mathrm{Cl})$ \\
\hline \multicolumn{6}{|l|}{ 1st model } \\
\hline Age, mean (SD) & $70.0(7.3)$ & $69.4(7.0)$ & 0.90 & 0.20 & $0.98(0.95-1.01)$ \\
\hline \multicolumn{6}{|l|}{ Gender } \\
\hline M & $187(73.9 \%)$ & $86(62.8 \%)$ & 0.03 & 0.007 & $1.96(1.20-3.18)$ \\
\hline $\mathrm{F}$ & $66(26.1 \%)$ & $51(37.2 \%)$ & & & \\
\hline Hypertension & $200(79.1 .5 \%)$ & $71(51.8 \%)$ & 0.001 & 0.001 & $0.29(0.18-0.47)$ \\
\hline Diabetes & $63(24.9 \%)$ & $31(22.6 \%)$ & 0.71 & 0.97 & $1.01(0.59-1.72)$ \\
\hline Smoking habit & $145(57.3 \%)$ & $82(59.9 \%)$ & 0.67 & 0.19 & $1.37(0.85-2.20)$ \\
\hline Dyslipidemia (high LDL-C) & $178(70.4 \%)$ & $79(57.7 \%)$ & 0.01 & 0.05 & $0.63(0.39-1.01)$ \\
\hline Obesity & $36(14.2 \%)$ & $7(5.1 \%)$ & 0.006 & 0.03 & $2.58(1.08-6.19)$ \\
\hline \multicolumn{6}{|l|}{ 2nd model } \\
\hline Metabolic syndrome & $96(38.1 \%)$ & $27(19.7 \%)$ & 0.001 & 0.001 & $2.55(1.61-4.90)$ \\
\hline Metabolic syndrome without obesity & $62(24.5 \%)$ & $21(15.3 \%)$ & 0.006 & 0.006 & $1.48(0.86-2.31)$ \\
\hline Metabolic syndrome with obesity & $33(13.0 \%)$ & $6(4.4 \%)$ & 0.001 & 0.003 & $3.97(1.81-6.22)$ \\
\hline
\end{tabular}


Table 3 Correlation between risk factors and cerebrovascular symptoms

\begin{tabular}{|c|c|c|c|c|c|}
\hline & \multirow{2}{*}{$\begin{array}{l}\text { Asymptomatic patients } \\
\mathrm{N}=125\end{array}$} & \multirow{2}{*}{$\begin{array}{l}\text { Symptomatic patients } \\
\mathrm{N}=265\end{array}$} & \multirow{2}{*}{$\begin{array}{l}\text { Univariate analysis } \\
\mathrm{p}\end{array}$} & \multicolumn{2}{|c|}{ Multivariate analysis } \\
\hline & & & & $\mathrm{p}$ & OR $(95 \% \mathrm{Cl})$ \\
\hline \multicolumn{6}{|l|}{ 1st model } \\
\hline Age, mean (SD) & $70.0(7.3)$ & $69.4(7.0)$ & 0.90 & 0.11 & $1.03(0.99-1.06)$ \\
\hline \multicolumn{6}{|l|}{ Gender } \\
\hline M & 79 (63.2\%) & $194(73.2 \%)$ & 0.06 & 0.02 & $0.57(0.35-0.92)$ \\
\hline $\mathrm{F}$ & $46(36.8 \%)$ & $71(28.8 \%)$ & & & \\
\hline Hypertension & $73(58.4 \%)$ & $198(74.7 \%)$ & 0.001 & 0.004 & $1.98(1.24-3.17)$ \\
\hline Diabetes & $29(23.2 \%)$ & $65(24.5 \%)$ & 0.80 & 0.86 & $0.96(0.56-1.62)$ \\
\hline Smoking habit & 75 (60.0\%) & $152(57.4 \%)$ & 0.66 & 0.31 & $0.78(0.49-1.25)$ \\
\hline Dyslipidemia (high LDL-C) & $72(57.6 \%)$ & 185 (69.8\%) & 0.02 & 0.04 & $1.64(1.03-2.61)$ \\
\hline Obesity & $6(4.8 \%)$ & $37(14.0 \%)$ & 0.006 & 0.02 & $0.34(0.14-0.86)$ \\
\hline \multicolumn{6}{|l|}{ 2nd model } \\
\hline Metabolic syndrome & $30(24.0 \%)$ & $93(35.2 \%)$ & 0.03 & 0.04 & $1.71(1.05-3.04)$ \\
\hline Metabolic syndrome without obesity & $24(20.2 \%)$ & $61(26.3 \%)$ & 0.24 & 0.26 & $1.17(0.71-1.88)$ \\
\hline Metabolic syndrome with obesity & $6(5.9 \%)$ & $33(16.2 \%)$ & 0.01 & 0.01 & $3.15(1.85-5.10)$ \\
\hline
\end{tabular}

Table 4 Correlation between risk factors and type of carotid plaques in male and female patients

\begin{tabular}{|c|c|c|c|c|c|c|c|c|}
\hline & \multicolumn{4}{|l|}{ Male patients } & \multicolumn{4}{|l|}{ Female patients } \\
\hline & \multirow{2}{*}{$\begin{array}{l}\text { Unstable plaques } \\
\mathrm{N}=187\end{array}$} & \multirow{2}{*}{$\begin{array}{l}\text { Stable plaques } \\
\mathrm{N}=86\end{array}$} & \multicolumn{2}{|c|}{ Multivariate analysis } & \multirow{2}{*}{$\begin{array}{l}\text { Unstable plaques } \\
N=66\end{array}$} & \multirow{2}{*}{$\begin{array}{l}\text { Stable plaques } \\
\mathrm{N}=51\end{array}$} & \multicolumn{2}{|c|}{ Multivariate analysis } \\
\hline & & & $\mathrm{p}$ & OR $(95 \% \mathrm{Cl})$ & & & $\mathrm{p}$ & OR $(95 \% \mathrm{Cl})$ \\
\hline Age, mean (SD) & $70.4(7.2)$ & $68.8(6.9)$ & 0.03 & $0.96(0.92-1.00)$ & $70.5(7.31)$ & $69.7(7.44)$ & 0.42 & $1.02(0.97-1.08)$ \\
\hline Hypertension & $146(78.1 \%)$ & $43(50.0 \%)$ & 0.001 & $0.27(0.15-0.49)$ & $54(81.8 \%)$ & $28(54.9 \%)$ & 0.005 & $0.29(0.12-0.69)$ \\
\hline Diabetes & $45(24.1 \%)$ & $20(23.3 \%)$ & 0.68 & $1.15(0.59-2.23)$ & $18(27.3 \%)$ & $11(21.6 \%)$ & 0.65 & $0.81(0.32-2.04)$ \\
\hline Smoking habit & $117(62.6 \%)$ & $58(67.4 \%)$ & 0.19 & $1.50(0.82-2.75)$ & $28(42.9 \%)$ & $24(47.1 \%)$ & 0.54 & $1.20(0.58-2.85)$ \\
\hline $\begin{array}{l}\text { Dyslipidemia (high } \\
\text { LDL-C) }\end{array}$ & $128(68.4 \%)$ & $46(53.5 \%)$ & 0.06 & $0.58(0.32-1.07)$ & $50(75.8 \%)$ & $33(64.7 \%)$ & 0.43 & $0.71(0.30-1.66)$ \\
\hline Obesity & $28(15.0 \%)$ & $3(3.5 \%)$ & 0.01 & $5.06(1.42-18.11)$ & $8(12.1 \%)$ & $4(7.8 \%)$ & 0.92 & $0.93(0.25-3.52)$ \\
\hline
\end{tabular}

Table 5 Effect of age in the correlation between risk factors, gender and type of plaques

\begin{tabular}{|c|c|c|c|c|c|c|c|c|}
\hline & \multicolumn{4}{|c|}{ Male patients $<70$ years } & \multicolumn{4}{|c|}{ Male patients $\geq 70$ years } \\
\hline & \multirow{2}{*}{$\begin{array}{l}\text { Unstable plaques } \\
\mathrm{N}=84\end{array}$} & \multirow{2}{*}{$\begin{array}{l}\text { Stable plaques } \\
\mathrm{N}=48\end{array}$} & \multicolumn{2}{|c|}{ Multivariate analysis } & \multirow{2}{*}{$\begin{array}{l}\text { Unstable plaques } \\
\mathrm{N}=103\end{array}$} & \multirow{2}{*}{$\begin{array}{l}\text { Stable plaques } \\
\mathrm{N}=38\end{array}$} & \multicolumn{2}{|c|}{ Multivariate analysis } \\
\hline & & & $p$ & OR $(95 \% \mathrm{Cl})$ & & & $p$ & OR $(95 \% \mathrm{Cl})$ \\
\hline Hypertension & $67(79.8 \%)$ & 25 (52.1\%) & 0.02 & $0.27(0.12-0.63)$ & 79 (76.7\%) & $18(47.4 \%)$ & 0.002 & $0.27(0.12-0.62)$ \\
\hline Diabetes & $24(28.6 \%)$ & 14 (29.2\%) & 0.52 & $1.34(0.55-3.30)$ & $21(20.4 \%)$ & $6(15.8 \%)$ & 0.90 & $0.93(0.32-2.71)$ \\
\hline Smoking habit & $63(75.0 \%)$ & 34 (70.8\%) & 0.88 & $1.07(0.44-2.59)$ & $54(52.4 \%)$ & $24(63.2 \%)$ & 0.12 & $1.97(0.84-4.58)$ \\
\hline $\begin{array}{l}\text { Dyslipidemia (high } \\
\text { LDL-C) }\end{array}$ & $65(77.4 \%)$ & $26(54.2 \%)$ & 0.04 & $0.42(0.18-0.95)$ & $63(61.2 \%)$ & $20(52.6 \%)$ & 0.86 & $4.57(0.38-1.97)$ \\
\hline Obesity & $16(19.0 \%)$ & $2(4.2 \%)$ & 0.03 & $5.91(1.17-29.80)$ & $12(11.7 \%)$ & $1(2.6 \%)$ & 0.16 & $4.61(0.54-39.19)$ \\
\hline
\end{tabular}

$30 \mathrm{~g} / \mathrm{m}^{2}$ and age $<70$ years, OR for unstable carotid was 5.91 (95\% CI 1.17-29.80), the highest OR compared to that of other risk factors. OR for unstable carotid plaque decreased to $4.61(95 \%$ CI $0.54-39.19)$ in males $\geq 70$ years (Table 5), whereas it resulted 0.93 (95\% CI $0.25-$ 3.52 ) in the women group (Table 4). 
Various clinical studies reported a significant association between obesity and risk of stroke, independently from the presence of other known cardiovascular risk factors [11-14]. Indeed, patients with a BMI in the $25-50 \mathrm{~kg} / \mathrm{m}^{2}$ range were shown in the Prospective Studies Collaboration (involving 900,000 patients) to have a $40 \%$ increased mortality from stroke [29]. Accordingly, the AHA recommends weight reduction in overweight $\left(\mathrm{BMI}=25-29 \mathrm{~kg} / \mathrm{m}^{2}\right)$ and obese $\left(\mathrm{BMI}>30 \mathrm{~kg} / \mathrm{m}^{2}\right)$ individuals, in order to reduce the risk of stroke [13].

The present study not only assessed the correlation between obesity and the occurrence of cerebrovascular symptoms, but also evaluated any association of obesity with the degree of atherosclerotic changes within carotids through histologic analysis of carotid plaques. Importantly, one of the targets of stroke prevention is the identification of plaques at high risk for rupture and thrombosis, i.e. so-called "vulnerable or unstable plaques" [18, 27]. Anatomic and clinical studies have demonstrated that acute cerebrovascular events are pathogenetically related to thrombosis and rupture of vulnerable atherosclerotic plaques, rather than to severity of stenosis $[18,27,30]$. To this end, many efforts have been recently made using non-invasive techniques aimed at identifying high risk plaques prone to rupture and thrombosis [31-34].

Results from our study support the negative impact of obesity in influencing other known risk factors for cardiovascular disease, increasing the risk of cerebrovascular disease and carotid plaque instability among patients with metabolic syndrome. As shown in Table 2, when obesity featured among metabolic syndrome risk factors, OR for plaque destabilization was 3.97 (95\% CI 1.81-6.22), a significantly higher value compared to OR in non-obese individuals with metabolic syndrome (= 1.48, 95\% CI 0.86-2.31). Similar results were obtained when assessing the occurrence of acute cerebrovascular symptoms (Table 3 ).

The observation that obesity represents an independent risk factor of plaque vulnerability only in male patients as supported by histological analysis corroborates data from both a recent large meta-analysis [35] and a duplex ultrasound study performed on 1686 patients with cerebrovascular disease [36]. Additionally, in another previous histological study performed on 457 CEA specimens from symptomatic and asymptomatic patients, our group had already observed that women had a significant lower prevalence of thrombotic plaques, as well as smaller necrotic core and hemorrhage extension [37]. Genderrelated differences in cardio- and cerebrovascular disease have been extensively demonstrated [36, 38-40]. Sex hormones seem to favor plaque stabilization, through their influence on endothelial function, lipid homeostasis, and inflammation. Several authors have hypothesized an age-dependent effect of estrogens, with a significant reduction of plaque inflammation being observed only in younger patients $[38,41]$. Notwithstanding, results of this as well as previous studies from our group [37] appear to show that also among post-menopausal women estrogens seem to have a stabilizing and protective effect on carotid arteries, as demonstrated by a significant lower number of inflammatory cells including macrophagic foam cells within the plaque cap of females as compared to men.

\section{Obesity and incidence of cardio and cerebrovascular diseases}

In the last decade, several studies have reported an unexpected and seemingly paradoxical inverse correlation between BMI and incidence of cardiovascular disease. Extensive clinical data from patients with congestive heart failure and ischemic heart disease seem to support the hypothesis that overweight and obese individuals benefit from a more favorable short- and long-term prognosis [2, 7-9]. These results have been corroborated by autopsy-related and histologic data revealing a lower incidence of coronary atherosclerosis in obese decedents [42, 43]. According to Brodsky et al. [10] morbid obesity seems to exert a protective effect also against developing severe aortic atherosclerosis, even if the pathogenetic mechanisms for such observation are yet to be explained.

On the contrary, other clinical studies failed to show the protective effects of obesity. The LEADER trial demonstrated a prevalence and cardiometabolic impact of obesity in cardiovascular high-risk patients with type 2 diabetes mellitus [44]. In addition, the Partners registry has demonstrated that compared to normal BMI there was an increased burden of CAD for BMI $>25 \mathrm{~kg} / \mathrm{m}^{2}$ [45]. According to these data, the results of our study do not seem to confirm such paradoxical effect of obesity on the cerebral circulation, especially in the cohort of male patients with an age $<70$ years; additionally, a neutral influence seems to exist among female patients (Table 4).

The discrepancy between our results and those obtained with a similar methodology in other vascular districts could be due to the fact that our study did not include the general population, but was rather limited to patients undergoing CEA due to symptomatic disease or presence of a carotid stenosis $>60 \%$. Accordingly, our study did not evaluate the absolute incidence of atherosclerotic disease, but rather was focused on the unstable atherosclerotic plaque since it represents the target for prevention studies.

\section{Obesity and aging}

Another significant clinical result from our study is the observation that risk of carotid plaque destabilization 



Fig. 1 Carotid plaque histology. a A stable fibroatheromatous plaque constituted by a large lipidic-necrotic core covered by a thick fibrous cap consisting principally of smooth muscle cells with few macrophages and T lymphocytes (Movat stain, $2 x$ ). b A stable plaque consisting mainly of fibrous tissue associated to the presence of calcifications (Movat stain, $2 x$ ). c An unstable ulcerated plaque characterized by a large disruption of the fibrous cap whereby the overlying acute thrombosis is in continuity with the underlying necrotic core (Movat stain, $1.5 \times$ ). d An unstable plaque with an acute thrombus in organization (Movat stain, 4x). Cap fibrous cap, Ath atheroma or lipid necrotic core, Cal calcification, Th acute thrombus

in obese patients is linked to age. Indeed, OR was highest in male patients aged $<70$ years. It was not possible to evaluate whether the risk increased in even younger patients as in our cases only 38 individuals were younger than 60 years. Despite this limitation, our results confirm data from other clinical studies reporting an inverse age-dependent association of BMI with all-cause mortality risk, including stroke mortality $[14,46]$. In this context, the Global BMI Mortality Collaboration study recently reported a detailed analysis about the correlation between BMI and all-cause mortality, including atherosclerotic disease, showing that BMI was greater in younger than older people and in men than women [47]. Furthermore, prevention of hypertension, obesity, and diabetes in patients aged 44-56 years may substantially prolong heart failure-free survival and decrease heart failure-related morbidity $[48,49]$.

\section{Study limitations}

Another possible limitation of our study is the criterion used to define obesity, since BMI, waist-to-hip ratio, or waist circumference have been employed to evaluate the presence of obesity in different studies. Data in the literature in this regard are conflicting. According to some authors, abdominal body fat might represent a stronger predictor of stroke risk than BMI [50]. Other studies reported that only BMI was significantly associated with stroke in male patients, whereas for female individuals the ideal criterion to define obesity appeared to be waist-to-hip ratio [51]. In our study the AHA definition of obesity was used [13], as we believe that BMI appears to be the most frequent anthropometric index employed to measure the obesity in the available literature $[52,53]$.

Moreover, mixing the whole patient population (symptomatic and asymptomatic) may have determined a bias in the results, since patients who already had a stroke also presented a different risk factor profile overall. It was not possible to perform separately the multivariate statistical analysis in the group of symptomatic and asymptomatic patients as the latter was only constituted of 125 cases with only 6 obese, 4 with TCFA and 2 with stable plaques. To overcome this limitation we evaluated the possible correlation of obesity with the instability of the carotid plaque which represents the true target for stroke prevention. 


\section{Conclusions}

In sum, the results from our study appear to do not confirm any paradoxical effect of obesity on the carotid artery district. Conversely, obesity is confirmed to be an independent risk factor for carotid plaque destabilization, particularly in males aged $<70$ years, significantly increasing such risk among patients with metabolic syndrome.

Further studies are required to assess the clinical implications of our data. We may speculate, however, that gender, along with age and type of atherosclerotic lesions (as assessed by imaging techniques) should be taken into account for a precise risk-stratification of obese patients.

\section{Abbreviations}

BMI: body mass index; CEA: carotid endarterectomy; AHA: American Heart Association; OR: estimated odds ratio; $95 \% \mathrm{Cl}$ : 95\% confidence interval; TCFA: thin-cap fibroatheroma.

\section{Authors' contributions}

VR, LA, NDD, MF and AM: study conception and design, acquisition of data, analysis and interpretation of data; MC. MS, AS, GS, EB, MM, IML, Al: acquisition of data, analysis and interpretation of data. All authors read and approved the final manuscript.

\section{Author details \\ ${ }^{1}$ Hypertension and Nephrology Unit, Department of Systems Medicine, University of Rome Tor Vergata, Rome, Italy. ${ }^{2}$ Anatomic Pathology, Depart- ment of Experimental Medicine and Surgery, University of Rome "Tor Vergata", Via Montpellier 1, 00133 Rome, Italy. ${ }^{3}$ Department of Biomedicine and Preven- tion, University of Rome "Tor Vergata", Via Montpellier 1, 00133 Rome, Italy. ${ }^{4}$ IRCCS San Raffaele, Via di Val Cannuta 247, 00166 Rome, Italy. ${ }^{5}$ OrchideaLab S.r.l, Via del Grecale 6, Morlupo, Rome, RM, Italy. ${ }^{6}$ Department of Systems Medicine, University of Rome Tor Vergata, Rome, Italy. ${ }^{7}$ Vascular Surgery, Department of Biomedicine and Prevention, University of Rome Tor Vergata, Rome, Italy.}

\section{Acknowledgements}

Not relevant.

\section{Competing interests}

All authors declare that they have no competing interests.

\section{Availability of data and materials}

The datasets used and/or analysed during the current study are available from the corresponding author on reasonable request.

\section{Consent for publication \\ Not applicable.}

\section{Ethics approval and consent to participate}

Study protocol adhered to ethical guidelines of the 1975 Declaration of Helsinki and was granted an a priori approval by the IRBs of our Institution.

\section{Funding}

Not relevant.

\section{Publisher's Note}

Springer Nature remains neutral with regard to jurisdictional claims in published maps and institutional affiliations.

Received: 9 January 2018 Accepted: 10 March 2018

Published online: 29 March 2018
References

1. Grundy SM, Cleeman II, Daniels SR, Donato KA, Eckel RH, Franklin BA, Gordon DJ, Krauss RM, Savage PJ, Smith SC Jr, et al. Diagnosis and management of the metabolic syndrome: an American Heart Association/ National Heart, Lung, and Blood Institute Scientific Statement. Circulation. 2005; 112(17):2735-52.

2. Lavie CJ, Milani RV, Ventura HO. Obesity and cardiovascular disease: risk factor, paradox, and impact of weight loss. J Am Coll Cardiol. 2009;53(21):1925-32.

3. Ortega FB, Lavie CJ, Blair SN. Obesity and cardiovascular disease. Circ Res. 2016:118(11):1752-70.

4. Pischon T, Boeing H, Hoffmann K, Bergmann M, Schulze MB, Overvad K, van der Schouw YT, Spencer E, Moons KG, Tjonneland A, et al. General and abdominal adiposity and risk of death in Europe. N Engl J Med. 2008;359(20):2105-20.

5. Wessel TR, Arant CB, Olson MB, Johnson BD, Reis SE, Sharaf BL, Shaw LJ, Handberg E, Sopko G, Kelsey SF, et al. Relationship of physical fitness vs body mass index with coronary artery disease and cardiovascular events in women. JAMA. 2004;292(10):1179-87.

6. Yusuf S, Hawken S, Ounpuu S, Bautista L, Franzosi MG, Commerford P, Lang CC, Rumboldt Z, Onen CL, Lisheng L, et al. Obesity and the risk of myocardial infarction in 27,000 participants from 52 countries: a casecontrol study. Lancet. 2005;366(9497):1640-9.

7. Romero-Corral A, Montori VM, Somers VK, Korinek J, Thomas RJ, Allison TG, Mookadam F, Lopez-Jimenez F. Association of bodyweight with total mortality and with cardiovascular events in coronary artery disease: a systematic review of cohort studies. Lancet. 2006;368(9536):666-78.

8. Angeras O, Albertsson P, Karason K, Ramunddal T, Matejka G, James S, Lagerqvist B, Rosengren A, Omerovic E. Evidence for obesity paradox in patients with acute coronary syndromes: a report from the Swedish Coronary Angiography and Angioplasty Registry. Eur Heart J. 2013;34(5):345-53.

9. Oreopoulos A, Padwal R, Kalantar-Zadeh K, Fonarow GC, Norris CM, McAlister FA. Body mass index and mortality in heart failure: a meta-analysis. Am Heart J. 2008;156(1):13-22.

10. Brodsky SV, Barth RF, Mo X, Yildiz V, Allenby P, Ivanov I, Moore S, Hitchcock $\mathrm{CL}$, Smith S, Sachak T, et al. An obesity paradox: an inverse correlation between body mass index and atherosclerosis of the aorta. Cardiovasc Pathol. 2016;25(6):515-20.

11. Kurth T, Gaziano JM, Rexrode KM, Kase CS, Cook NR, Manson JE, Buring JE. Prospective study of body mass index and risk of stroke in apparently healthy women. Circulation. 2005;111(15):1992-8.

12. Strazzullo P, D’Elia L, Cairella G, Garbagnati F, Cappuccio FP, Scalfi L. Excess body weight and incidence of stroke: meta-analysis of prospective studies with 2 million participants. Stroke. 2010;41(5):e418-26.

13. Meschia JF, Bushnell C, Boden-Albala B, Braun LT, Bravata DM, Chaturvedi S, Creager MA, Eckel RH, Elkind MS, Fornage M, et al. Guidelines for the primary prevention of stroke: a statement for healthcare professionals from the American Heart Association/American Stroke Association. Stroke. 2014;45(12):3754-832.

14. Mitchell AB, Cole JW, McArdle PF, Cheng YC, Ryan KA, Sparks MJ, Mitchell $B D$, Kittner $S J$. Obesity increases risk of ischemic stroke in young adults. Stroke. 2015:46(6):1690-2.

15. Ovbiagele B, Bath PM, Cotton D, Vinisko R, Diener HC. Obesity and recurrent vascular risk after a recent ischemic stroke. Stroke. 2011;42(12):3397-402.

16. Vemmos K, Ntaios G, Spengos K, Savvari P, Vemmou A, Pappa T, Manios E, Georgiopoulos G, Alevizaki M. Association between obesity and mortality after acute first-ever stroke: the obesity-stroke paradox. Stroke. 2011;42(1):30-6.

17. Barba R, Marco J, Ruiz J, Canora J, Hinojosa J, Plaza S, Zapatero-Gaviria A. The obesity paradox in stroke: impact on mortality and short-term readmission. J Stroke Cerebrovasc Dis. 2015;24(4):766-70.

18. Spagnoli LG, Mauriello A, Sangiorgi G, Fratoni S, Bonanno E, Schwartz RS, Piepgras DG, Pistolese R, Ippoliti A, Holmes DR Jr. Extracranial thrombotically active carotid plaque as a risk factor for ischemic stroke. JAMA. 2004;292(15):1845-52.

19. Golledge J, Greenhalgh RM, Davies AH. The symptomatic carotid plaque. Stroke. 2000;31(3):774-81. 
20. Mauriello A, Sangiorgi GM, Virmani R, Trimarchi S, Holmes DR Jr, Kolodgie FD, Piepgras DG, Piperno G, Liotti D, Narula J, et al. A pathobiologic link between risk factors profile and morphological markers of carotid instability. Atherosclerosis. 2010;208(2):572-80.

21. Chobanian AV, Bakris GL, Black HR, Cushman WC, Green LA, Izzo JL Jr, Jones DW, Materson BJ, Oparil S, Wright JT Jr, et al. Seventh report of the Joint National Committee on Prevention, Detection, Evaluation, and Treatment of High Blood Pressure. Hypertension. 2003;42(6):1206-52.

22. Whelton PK, Carey RM, Aronow WS, Casey DE Jr, Collins KJ, Dennison Himmelfarb C, DePalma SM, Gidding S, Jamerson KA, Jones DW, et al. 2017 ACC/AHA/AAPA/ABC/ACPM/AGS/APhA/ASH/ASPC/NMA/PCNA Guideline for the Prevention, Detection, Evaluation, and Management of High Blood Pressure in Adults: A Report of the American College of Cardiology/American Heart Association Task Force on Clinical Practice Guidelines. J Am Coll Cardiol. 2017. https://doi.org/10.1016/j.jacc.2017.11.006.

23. Stone NJ, Robinson JG, Lichtenstein AH, Bairey Merz CN, Blum CB, Eckel RH, Goldberg AC, Gordon D, Levy D, Lloyd-Jones DM, et al. 2013 ACC/ AHA guideline on the treatment of blood cholesterol to reduce atherosclerotic cardiovascular risk in adults: a report of the American College of Cardiology/American Heart Association Task Force on Practice Guidelines. Circulation. 2014;129(25 Suppl 2):S1-45.

24. Friedewald WT, Levy RI, Fredrickson DS. Estimation of the concentration of low-density lipoprotein cholesterol in plasma, without use of the preparative ultracentrifuge. Clin Chem. 1972;18(6):499-502.

25. Mauriello A, Servadei F, Sangiorgi G, Anemona L, Giacobbi E, Liotti D, Spagnoli LG. Asymptomatic carotid plaque rupture with unexpected thrombosis over a non-canonical vulnerable lesion. Atherosclerosis. 2011;218(2):356-62

26. Bischetti S, Scimeca M, Bonanno E, Federici M, Anemona L, Menghini R, Casella S, Cardellini M, Ippoliti A, Mauriello A. Carotid plaque instability is not related to quantity but to elemental composition of calcification. Nutr Metab Cardiovasc Dis. 2017;27(9):768-74.

27. Virmani R, Kolodgie FD, Burke AP, Farb A, Schwartz SM. Lessons from sudden coronary death: a comprehensive morphological classification scheme for atherosclerotic lesions. Arterioscler Thromb Vasc Biol. 2000;20(5):1262-75.

28. Mauriello A, Sangiorgi G, Virmani R, Servadei F, Trimarchi S, Holmes DR Jr, Kolodgie F, Biondi Zoccai G, Leuzzi C, Spagnoli LG. Evidence of a topographical link between unstable carotid plaques and luminal stenosis: can we better stratify asymptomatic patients with significant plaque burden? Int J Cardiol. 2012;155(2):309-11.

29. Whitlock G, Lewington S, Sherliker P, Clarke R, Emberson J, Halsey J, Qizilbash N, Collins R, Peto R. Body-mass index and cause-specific mortality in 900,000 adults: collaborative analyses of 57 prospective studies. Lancet. 2009;373(9669):1083-96.

30. Redgrave JN, Lovett JK, Gallagher PJ, Rothwell PM. Histological assessment of 526 symptomatic carotid plaques in relation to the nature and timing of ischemic symptoms: the Oxford plaque study. Circulation. 2006;113(19):2320-8.

31. Gupta A, Baradaran H, Schweitzer AD, Kamel H, Pandya A, Delgado D, Dunning A, Mushlin Al, Sanelli PC. Carotid plaque MRI and stroke risk: a systematic review and meta-analysis. Stroke. 2013;44(11):3071-7.

32. Huibers A, de Borst GJ, Wan S, Kennedy F, Giannopoulos A, Moll FL, Richards T. Non-invasive carotid artery imaging to identify the vulnerable plaque: current status and future goals. Eur JVasc Endovasc Surg. 2015;50(5):563-72.

33. Brinjikji W, Rabinstein AA, Lanzino G, Murad MH, Williamson EE, DeMarco $J K$, Huston J 3rd. ultrasound characteristics of symptomatic carotid plaques: a systematic review and meta-analysis. Cerebrovasc Dis. 2015:40(3-4):165-74.

34. Fabiano S, Mancino S, Stefanini M, Chiocchi M, Mauriello A, Spagnoli LG, Simonetti G. High-resolution multicontrast-weighted MR imaging from human carotid endarterectomy specimens to assess carotid plaque components. Eur Radiol. 2008;18(12):2912-21.

35. Stoberock K, Debus ES, Atlihan G, Daum G, Larena-Avellaneda A, Eifert S, Wipper S. Gender differences in patients with carotid stenosis. Vasa. 2016;45(1):11-6.
36. Iemolo F, Martiniuk A, Steinman DA, Spence JD. Sex differences in carotid plaque and stenosis. Stroke. 2004;35(2):477-81.

37. Sangiorgi G, Roversi S, Biondi Zoccai G, Modena MG, Servadei F, Ippoliti A, Mauriello A. Sex-related differences in carotid plaque features and inflammation. J Vasc Surg. 2013;57(2):338-44.

38. Manson JE, Hsia J, Johnson KC, Rossouw JE, Assaf AR, Lasser NL, Trevisan $M$, Black HR, Heckbert SR, Detrano R, et al. Estrogen plus progestin and the risk of coronary heart disease. N Engl J Med. 2003;349(6):523-34.

39. Maric-Bilkan C, Arnold AP, Taylor DA, Dwinell M, Howlett SE, Wenger N, Reckelhoff JF, Sandberg K, Churchill G, Levin E, et al. Report of the National Heart, Lung, and Blood Institute Working Group on Sex Differences Research in Cardiovascular Disease: scientific questions and challenges. Hypertension. 2016;67(5):802-7.

40. Arnold AP, Cassis LA, Eghbali M, Reue K, Sandberg K. Sex hormones and sex chromosomes cause sex differences in the development of cardiovascular diseases. Arterioscler Thromb Vasc Biol. 2017;37(5):746-56.

41. Xing D, Nozell S, Chen YF, Hage F, Oparil S. Estrogen and mechanisms of vascular protection. Arterioscler Thromb Vasc Biol. 2009:29(3):289-95.

42. Kortelainen ML. Myocardial infarction and coronary pathology in severely obese people examined at autopsy. Int J Obes Relat Metab Disord. 2002;26(1):73-9.

43. Rastogi P, Pinto DS, Pai MR, Kanchan T. An autopsy study of coronary atherosclerosis and its relation to anthropometric measurements/indices of overweight and obesity in men. J Forensic Leg Med. 2012;19(1):12-7.

44. Masmiquel L, Leiter LA, Vidal J, Bain S, Petrie J, Franek E, Raz I, Comlekci A, Jacob S, van Gaal L, et al. LEADER 5: prevalence and cardiometabolic impact of obesity in cardiovascular high-risk patients with type 2 diabetes mellitus: baseline global data from the LEADER trial. Cardiovasc Diabetol. 2016:15:29.

45. Hulten EA, Bittencourt MS, Preston R, Singh A, Romagnolli C, Ghoshhajra B, Shah R, Abbasi S, Abbara S, Nasir K, et al. Obesity, metabolic syndrome and cardiovascular prognosis: from the Partners coronary computed tomography angiography registry. Cardiovasc Diabetol. 2017;16(1):14

46. Kernan WN, Dearborn JL. Obesity increases stroke risk in young adults: opportunity for prevention. Stroke. 2015;46(6):1435-6.

47. Global BMIMC, Di Angelantonio E, Bhupathiraju SN, Wormser D, Gao P, Kaptoge S, BerringtondeGonzalez A, Cairns BJ, Huxley R, Jackson CL, et al. Body-mass index and all-cause mortality: individual-participantdata meta-analysis of 239 prospective studies in four continents. Lancet. 2016:388(10046):776-86

48. Ahmad FS, Ning H, Rich JD, Yancy CW, Lloyd-Jones DM, Wilkins JT. Hypertension, obesity, diabetes, and heart failure-free survival: the cardiovascular disease lifetime risk pooling project. JACC Heart Fail. 2016;4(12):911-9.

49. Kumar S, Sharma V. Hypertension, obesity, diabetes, and heart failure-free survival: the cardiovascular disease lifetime risk pooling project in New Delhi, India. Atherosclerosis. 2017;263:e159.

50. Suk SH, Sacco RL, Boden-Albala B, Cheun JF, Pittman JG, Elkind MS, Paik MC. Abdominal obesity and risk of ischemic stroke: the Northern Manhat$\tan$ Stroke Study. Stroke. 2003;34(7):1586-92.

51. Kizer JR, Biggs ML, IX JH, Mukamal KJ, Zieman SJ, de Boer IH, Mozaffarian D, Barzilay Jl, Strotmeyer ES, Luchsinger JA, et al. Measures of adiposity and future risk of ischemic stroke and coronary heart disease in older men and women. Am J Epidemiol. 2011:173(1):10-25.

52. Lu Y, Hajifathalian K, Ezzati M, Woodward M, Rimm EB, Danaei G. Metabolic mediators of the effects of body-mass index, overweight, and obesity on coronary heart disease and stroke: a pooled analysis of 97 prospective cohorts with 1.8 million participants. Lancet. 2014;383(9921):970-83.

53. Forouzanfar MH, Alexander L, Anderson HR, Bachman VF, Biryukov S, Brauer M, Burnett R, Casey D, Coates MM, Cohen A, et al. Global, regional, and national comparative risk assessment of 79 behavioural, environmental and occupational, and metabolic risks or clusters of risks in 188 countries, 1990-2013: a systematic analysis for the Global Burden of Disease Study 2013. Lancet. 2015;386(10010):2287-323. 